\title{
Anthropometric indicators as a discriminator of sarcopenia in community- dwelling older adults of the Amazon region: a cross-sectional study
}

Cássio Lima Esteves, Daniela Gonçalves Ohara, Areolino Pena Matos, Vânia T. K. Ferreira, Natalia C. R. losimuta and Maycon Sousa Pegorari* (i)

\begin{abstract}
Background: Sarcopenia is a geriatric syndrome associated with negative health outcomes and the use of viable alternative screening tools may help in the diagnosis of this condition. This study aimed to analyze the association of sarcopenia with anthropometric indicators among community-dwelling older adults and to identify cut-off points for such indicators as a discriminant criterion for predicting sarcopenia.

Methods: This was a cross-sectional study conducted on community-dwelling older adults $\geq 60$ years old $(n=411)$ of both sexes from Macapá, Amapá, Brazil. Socioeconomic, clinical and anthropometric data (arm circumference AC, waist circumference - WC, calf circumference - CC and body mass index - BMI) were collected using a structured form. Sarcopenia was identified according to the EWGSOP 2 consensus. The association between anthropometric indicators and sarcopenia was performed using logistic regression and cut-off points established from the ROC Curve. Statistical significance was defined as $p \leq 0.05$.

Results: Adjusted analysis indicated an independent and inverse association between sarcopenia and the anthropometric indicators: AC (odds ratio, OR: 0.63; 95\% confidence interval, 95\%Cl: 0.53-0.76), CC (OR: 0.73; 95\%Cl: 0.62-0.85), WC (OR: 0.93; 95\%Cl: 0.90-0.97) and BMI (OR: 0.64; 95\%Cl: 0.53-0.76). The following cut-off points for older men and women represented the discriminant criterion for the presence of sarcopenia: WC $(\leq 97$ and $\leq 86$ $\mathrm{cm}), C C(\leq 33$ and $\leq 31 \mathrm{~cm}), A C(\leq 27 \mathrm{~cm})$ and BMI $\left(\leq 24.8 \mathrm{~kg} / \mathrm{m}^{2}\right.$ and $\left.\leq 24.5 \mathrm{~kg} / \mathrm{m}^{2}\right)$ (area under the ROC curve superior to 0.70$)$. BMI and AC were the indicators with the highest ability to discriminate older adults of both sexes with sarcopenia.
\end{abstract}

Conclusions: An increase of one unit of the indicators can reduce the probability of occurrence of sarcopenia. All indicators were considered to discriminate the occurrence of sarcopenia, with emphasis on BMI and AC, and could be used to screen for this condition among community-dwelling older adults.

Keywords: Sarcopenia, Anthropometry, Older adult health, Urban population

\footnotetext{
* Correspondence: mayconpegorari@yahoo.com.br

Physical Therapy Course, Department of Biological and Health Sciences, Federal University of Amapá, Road Juscelino Kubitschek, Km - 02, Jardim Marco Zero, Macapá, Amapá CEP 68903-419, Brazil
}

C C The Author(s). 2020 Open Access This article is licensed under a Creative Commons Attribution 4.0 International License, which permits use, sharing, adaptation, distribution and reproduction in any medium or format, as long as you give appropriate credit to the original author(s) and the source, provide a link to the Creative Commons licence, and indicate if changes were made. The images or other third party material in this article are included in the article's Creative Commons licence, unless indicated otherwise in a credit line to the material. If material is not included in the article's Creative Commons licence and your intended use is not permitted by statutory regulation or exceeds the permitted use, you will need to obtain permission directly from the copyright holder. To view a copy of this licence, visit http://creativecommons.org/licenses/by/4.0/. The Creative Commons Public Domain Dedication waiver (http://creativecommons.org/publicdomain/zero/1.0/) applies to the data made available in this article, unless otherwise stated in a credit line to the data. 


\section{Background}

Sarcopenia is a muscle disease with cumulative characteristics in lifetime, defined by low levels of muscle strength, muscle quantity/quality and physical performance [1]. The condition is associated with negative health outcomes among older adults, impairing functional ability and the quality of life, causing falls and fractures, and involving high health care costs and mortality rates [2]. Its prevalence is 1 to $29 \%$ among community-dwelling older adults [2] and about $17 \%$ in the older Brazilian population [3].

In view of the impact of sarcopenia on the public health area, an early identification of the condition becomes relevant [4]. The diagnosis can be made by determining a reduction of muscle mass accompanied by reduced muscle strength and/or reduced physical performance, the latter conditions being assessed by dynamometry and gait speed, respectively [5]. Dualenergy X-ray emission absorptiometry (DXA), magnetic resonance (MR) or computed tomography (CT) are specifically recommended for the assessment of low muscle quality and quantity. However, these are expensive methods involving the risk of exposure to radiation and are little available to the public [6]. Thus, simpler low-cost, noninvasive and easily applicable methods such as anthropometry may represent viable alternative screening tools helping the diagnosis of sarcopenia $[7,8]$.

Several studies have pointed out the use of anthropometry for the screening of sarcopenia [5, 8-10], however these studies has been performed in different countries with different life-style as Australia, Korea, Japan and Turkey, which make difficult generalize data from them to use in South American countries. In addition, the World Health Organization (WHO) [11] considers calf circumference (CC) to be a more sensitive anthropometric index of muscle mass among older adults, although arm circumference (AC), Abdominal circumference $(\mathrm{AbC})$ and body mass index (BMI) have also been used and documented in the scientific literature as predictors of sarcopenia $[9,12]$.

Studies conducted in Brazil are recent and have determined the viability of $\mathrm{CC}$ as a discriminator of muscle mass in older adults [13, 14], as well as BMI [15], waistheight ratio and waist circumference identified with DXA [7]. Besides, the majority of this studies have been mostly performed and developed in specifics regions or states in Brazil [3]. Thus, there are few studies conducted in the northern region of Brazil that investigate how these older adults are getting older and if they are sarcopenic. This information is important, mainly because the Northern Brazil region, or more specifically in Macapá city, the Amazon region, is located in one of the least developed regions of the country, which fortify the technological resource scarcity, considered the gold standard instrument to assess sarcopenia.

According to data estimated [16], in the year 2010, the city of Macapá had $16 \%$ of the population living in the subnormal agglomerations, or places with no planning and situated in areas considered as inappropriate called areas of "ressaca", "baixadas" or stilt. The areas of "ressaca" cover $20 \%$ of the city's urban perimeter [17], "they behave like natural water reservoirs in a complex and distinct ecosystem and suffering the effects of tidal action through an intricate network of canals and streams plus the seasonal rain cycle" [18]. For this, the subnormal agglomerations areas are locations which are low socioeconomic conditions and difficult to access readily, which make hard the dislocation of the residents from their houses to hospitals or the access of basic healthcare professionals. Thus, there is an urgent necessity to adopt easy-to-use instruments as anthropometric indicators to identify geriatrics syndromes as sarcopenia in these areas, once it is impossible take huge or expensive equipment in these areas.

In view of the scarcity of studies validating anthropometric measures as screening tools for sarcopenia among older persons, according to Cruz-Jentoft et al. [19], it is to be believed that such indicators may represent a viable and additional alternative to be used to facilitate screening in order to guide the diagnosis of sarcopenia and the appropriate interventions, with an impact on health care for the older population, especially in areas of the Brazilian Amazon region. Besides, validating the anthropometric measures and finding the cut-off points to determine the sarcopenia condition, it will be possible to analyze if this data is different from the other studies and understand the impact of environmental factors on the living conditions of population from the Northern Brazil region.

Thus, the objectives of the present study were to analyze the association between sarcopenia and anthropometric indicators among community-living older subjects and to identify cut-off points for the anthropometric indicators as a discriminant criterion for the prediction of sarcopenia.

\section{Methods}

\section{Context and study population}

This was a cross-sectional study conducted on 411 older adults residing in the urban area of Macapá, in 2017. Information about the characteristics of the population and sample calculation, as well as the procedures for data collection are available in a previously published study [20]. The present study was approved by the Research Ethics Committee (protocol ${ }^{\circ} 1.738 .671$ ).

The study was conducted on subjects aged 60 years or older who resided in the urban area of the municipality 
of Macapá, able to walk with or without help, and who gave written informed consent to participate. Subjects who could not be located after three attempts by the interviewer, who had moved to another city, who were hospitalized and who had neurological sequelae and/or conditions that would not permit their assessment, were excluded.

Also excluded were subjects with cognitive decline that would prevent them from responding to the questions of the interviewer and from performing the tests, as determined by the translated version of the Mini Mental State Examination (MMSE) validated for Brazil, which considers cut-off points based on schooling level [21].

\section{Instruments for data collection}

\section{Sarcopenia (dependent variable)}

Sarcopenia was established using the operational definition recommended by the European Working Group on Sarcopenia in Older People (EWGSOP) 2 and the diagnosis considered the associated of low muscle strength and low muscle mass [19]:

1- Low muscle mass: The muscle mass component was measured based on the total muscle mass (TMM) estimated by the equation proposed by Lee et al. [22], validated for use in Brazilian elderly [23] and used in previous population-based studies [20, 24]: [MMT $(\mathrm{kg})=(0.244 \mathrm{x}$ body weight $)+(7.8 \mathrm{x}$ height $)-(0.098 \mathrm{x}$ age $)+(6.6 x$ sex $)+($ ethnicity -3.3$)]$. The equation considers the parameters body mass, height, sex, age and race. For the sex variable, $0=$ women and $1=$ men; for ethnicity, $0=$ white and indigenous, $-1.2=$ yellow and $1.4=$ black and brown were adopted. Based on the $\mathrm{TMM}$, the muscle mass index (MMI = TMM / height2) was calculated. The cut-off point for muscle mass index (MMI) in the present study considered the 20th percentile of the sample studied, according to previous studies $[25,26]$ and represented values $<9.61$ $\mathrm{kg} / \mathrm{m} 2$ for men and $<6.92 \mathrm{~kg} / \mathrm{m} 2$ for women [20, 24].

2 Reduction of muscle strength was measured with a manual hydraulic dynamometer, SAEHAN ${ }^{\circ}$ Hydraulic Hand Dynamometer, model SH5001, using handgrip strength (HGS) in an isometric manner based on $\mathrm{kg} /$ force (kgf) as recommended by the American Society of Hand Therapists [27]. Three measurements were made at one-minute intervals in the dominant limb and their mean value was considered. Values of less than $27 \mathrm{kgf}$ for men and less than $16 \mathrm{kgf}$ for women were considered to indicate reduced muscle strength [28].

\section{Anthropometric indicators (independent variable)}

The following anthropometric indicators were assessed in the present study: Body Mass Index (BMI), calf circumference (CC), waist circumference (WC), and arm circumference $(\mathrm{AC})$. The perimeters/circumferences were measured with an inelastic tape. BMI was determined with a portable digital scale (Whole Body Control Scale, Omron, Model HBF 514C, $150 \mathrm{~kg}$ ), with the subject barefoot and wearing the minimum amount of clothing possible. As recommended, the height was measured with the person barefoot, standing straight with joined feet and with the heels, buttocks and head in contact with the wall, keeping his eyes fixed on a horizontal axis parallel to the floor. BMI was defined as $\mathrm{kg} / \mathrm{height}^{2}[29,30]$.

$\mathrm{AC}$ was measured at the midpoint between acromion and olecranon in the arm of the subject resting against his body in a relaxed manner [31, 32]. CC can be measured on the point of largest perimeter of the right or left leg, with the subject sitting or lying in dorsal decubitus without contracting the calf muscles [33]. In the present study we measured the left leg with the subject in the sitting position.

WC was measured using the protocol recommended by the WHO [34], i.e., at the approximate midpoint between the lower margin of the last palpable rib and the top of the iliac crest. Other elements were considered like as posture, breathing phase and abdominal tension. The posture recommended here was orthostatic position, arms along the sides of the body, joined feet and weight uniformly distributed between them. WC should be measured at the end of a normal expiration, and abdominal tension at the measuring point should be avoided, i.e., the subject should remain relaxed during the measurement $[34,35]$.

\section{Adjustment variables}

Variables such as age, sex, schooling, income, health perception, number of diseases and medications, hospitalization, and the occurrence of falls in the last ear were recorded on a structured form. The subjects were asked to report the use of tobacco and its duration (years) (yes/no). Functional capacity was assessed using the Katz independence Scale for basic activities of daily life (BADL) [36] and the Lawton and Brody scale [37] for instrumental activities of daily life (IADL). Older adults who did not show difficulty in performing any BADL or IADL were considered to be independent, while subjects with difficulty in performing one or more activity were considered to be dependent. The level of physical activity was determined using the long version of the International Physical Activity Questionnaire (IPAQ) [33]. Subjects were considered to be sufficiently active when they engaged in vigorous physical activity for $150 \mathrm{~min}$ or more per week and subjects who engaged in 0 to 149 min of vigorous or moderate weekly activity per week were considered to be inactive. The complete version of the interview guide is available in Additional file 1. 
Table 1 Characteristics of the older adults according to sarcopenia

\begin{tabular}{|c|c|c|c|c|}
\hline Variables & $\begin{array}{l}\text { Sarcopenic } \\
(n=25)\end{array}$ & $\begin{array}{l}\text { Non-sarcopenic } \\
(n=386)\end{array}$ & $p^{*}$ Value & $\begin{array}{l}\text { Total } \\
\text { sample } \\
(n=411)\end{array}$ \\
\hline Age (years) & $77.04 \pm 8.99$ & $69.69 \pm 6.90$ & $<0.001$ & $70.15 \pm 7.25$ \\
\hline \multicolumn{5}{|l|}{ Sex } \\
\hline Male & $10(40)$ & $128(33.2)$ & \multirow[t]{2}{*}{0.483} & 138 (33.6) \\
\hline Female & $15(60)$ & $258(66.8)$ & & $273(66.4)$ \\
\hline Height (m) & $1.51(1.46-1.58)$ & $1.54(1.48-1.60)$ & 0.244 & $1.52(1.48-1.60)$ \\
\hline Weight (kg) & $50.28 \pm 7.96$ & $67.86 \pm 12.86$ & $<0.001$ & $66.79 \pm 12.29$ \\
\hline Schooling (years) & $3(1.5-7)$ & $5(2-10)$ & 0.202 & $4(2-10)$ \\
\hline \multicolumn{5}{|l|}{ Income } \\
\hline None & $1(4)$ & $43(11.1)$ & \multirow[t]{3}{*}{0.311} & $44(10.7)$ \\
\hline 1 minimum wage or less & $15(60)$ & $178(46.1)$ & & $193(47)$ \\
\hline 2 minimum wages or more & $9(36)$ & $165(42.7)$ & & $174(42.3)$ \\
\hline \multicolumn{5}{|l|}{ Health perception } \\
\hline Positive & $8(32)$ & $116(30.1)$ & \multirow[t]{2}{*}{0.844} & $124(30.2)$ \\
\hline Negative & $17(68)$ & $269(69.9)$ & & $286(69.8)$ \\
\hline $\operatorname{MMl}\left(\mathrm{kg} / \mathrm{m}^{2}\right)$ & $7.17 \pm 1.56$ & $9.02 \pm 1.70$ & $<0.001$ & $8.91 \pm 1.74$ \\
\hline HGS (kgf) & $16.52 \pm 4.73$ & $25.18 \pm 8.96$ & $<0.001$ & $24.65 \pm 9.01$ \\
\hline Number of diseases & $4(3-7)$ & $5(3-7)$ & 0.803 & $5(3-7)$ \\
\hline Number of medications & $1(0-2)$ & $1(0-3)$ & 0.534 & $1(0-3)$ \\
\hline \multicolumn{5}{|l|}{ Falls in the last year } \\
\hline Yes & $2(8)$ & $81(21)$ & \multirow[t]{2}{*}{0.117} & $83(20.2)$ \\
\hline No & $23(92)$ & $305(79)$ & & $328(79.8)$ \\
\hline \multicolumn{5}{|l|}{ Hospitalization in the last year } \\
\hline Yes & $5(20)$ & $53(13.7)$ & \multirow[t]{2}{*}{0.485} & $58(14.1)$ \\
\hline No & $20(80)$ & $333(86.3)$ & & $353(85.9)$ \\
\hline \multicolumn{5}{|l|}{ Smoking habit } \\
\hline Yes & $4(16)$ & $35(9.1)$ & \multirow[t]{2}{*}{0.289} & $39(9.5)$ \\
\hline No & $21(84)$ & $351(90.9)$ & & $372(90.5)$ \\
\hline \multicolumn{5}{|l|}{ Physical activity } \\
\hline Sufficiently active & $9(36)$ & $209(54.1)$ & \multirow[t]{2}{*}{0.078} & $218(53)$ \\
\hline Insufficiently active & $16(64)$ & $177(45.9)$ & & $193(47)$ \\
\hline \multicolumn{5}{|l|}{ Dependence (Katz Scale) } \\
\hline Yes & $2(8)$ & $28(7.3)$ & \multirow[t]{2}{*}{0.891} & $30(7.3)$ \\
\hline No & $23(92)$ & $358(92.7)$ & & $381(92.7)$ \\
\hline \multicolumn{5}{|c|}{ Dependence (Lawton and Brody Scale) } \\
\hline Yes & $20(80)$ & $266(68.9)$ & \multirow[t]{2}{*}{0.243} & $286(69.6)$ \\
\hline No & $5(20)$ & $120(31.1)$ & & $125(30.4)$ \\
\hline Body mass index (BMI) & $21.69 \pm 2.12$ & $28.53 \pm 4.81$ & $<0.001$ & $28.11 \pm 4.97$ \\
\hline Calf circumference (CC) & $29.57 \pm 2.64$ & $33.45 \pm 3.81$ & $<0.001$ & $33.22 \pm 3.86$ \\
\hline Arm circumference (AC) & $24.10 \pm 2.29$ & $29.51 \pm 3.70$ & $<0.001$ & $29.18 \pm 3.85$ \\
\hline Waist circumference (WC) & 90 (79.75-96) & $98(90-105)$ & $<0.001$ & $97(90-105)$ \\
\hline
\end{tabular}

Data are reported as $\mathrm{n}$ : number of subjects; mean \pm standard deviation; median (interquartile range); m: meters; kg: kilogram; MMI: muscle mass index; HGS: handgrip strength; kgf: kilogram force; Chi-square test, Student t-test and MannWhitney U test; * $p<0.05$ 


\section{Statistical analysis}

Data are reported as means, standard deviations, median (interquartile range), absolute number, and percentage. Comparative analysis between the sarcopenic and nonsarcopenic groups was carried out using the Student ttest and Mann Whitney $U$ test, according to the data distribution verified by the Kolmogorov-Smirnov test, for the quantitative variables and the chi-square test for the categorical variables. The association between anthropometric indicators (independent variable) and sarcopenia (dependent variable) was determined by crude and adjusted analysis using the logistic regression model and the estimate of the odds ratio (OR), with the 95\% confidence interval $(95 \% \mathrm{CI})$, and the level of significance set at $5 \%(p<0.05)$. The Hosmer and Lemeshow test $(p>0.05)$ was applied to analyze the degree of model fit. All analyses were carried out using the Statistical Package for the Social Sciences (SPSS) version 21.0.

Receiver Operating Characteristic (ROC) curves were constructed to determine the cut-off points of the anthropometric indicators as discriminators of sarcopenia, and the area under the ROC curve (AUC), the sensitivity and specificity were determined using the MedCalc 11.4.4 software, with $95 \% \mathrm{CI}$ and a $5 \%$ level of significance $(p<0.05)$.

\section{Results}

The final sample consisted of 411 older adults recruited on the basis of inclusion and exclusion criteria. The characteristics of the selected subjects are listed in Table 1. The prevalence of sarcopenia was $6.1 \%(n=25)$. Sarcopenic subjects had lower values of anthropometric indicators than non-sarcopenic subjects $(p<0.05)$ (Table 1$)$.

Table 2 presents the adjusted analysis and indicates an independent and inverse association between sarcopenia and the anthropometric indicators, with the increase of one unit of $\mathrm{BMI}, \mathrm{AC}, \mathrm{CC}$ and $\mathrm{WC}$ reducing the probability of the subjects to have sarcopenia by approximately $36,37,27$ and $7 \%$, respectively.

The results of the area under the ROC curve indicated coefficients higher than 0.7 , representing acceptable discrimination (Figs. 1 and 2). The cut-off points for the older men and women, respectively, represented the discriminant criterion for the presence of sarcopenia, as follows: WC ( $\leq 97$ and $\leq 86 \mathrm{~cm}), \mathrm{CC}(\leq 33$ and $\leq 31 \mathrm{~cm})$, AC $(\leq 27 \mathrm{~cm})$ and BMI $\left(\leq 24.8 \mathrm{~kg} / \mathrm{m}^{2}\right.$ and $\left.\leq 24.5 \mathrm{~kg} / \mathrm{m}^{2}\right)(p<$ 0.05) [38]. BMI and AC were the indicators with the higher ability to discriminate older subjects with sarcopenia of both sexes.

\section{Discussion}

The present study demonstrated an association between all anthropometric indicators and sarcopenia among
Table 2 Association between sarcopenia and anthropometric indicators among community-dwelling older adults

\begin{tabular}{llll}
\hline Variables & \multicolumn{2}{l}{ Sarcopenia } \\
\cline { 2 - 3 } Anthropometric indicators & OR & $\mathbf{9 5 \% C l}$ & $\boldsymbol{p}^{*}$ Value \\
\hline Body mass index (BMI) & 0.66 & $0.57-0.76$ & $<0.001$ \\
$\quad$ Unadjusted & 0.64 & $0.53-0.76$ & $<0.001$ \\
$\quad$ Adjusted & & & \\
Calf circumference (CC) & 0.73 & $0.64-0.83$ & $<0.001$ \\
$\quad$ Unadjusted & 0.73 & $0.62-0.85$ & $<0.001$ \\
$\quad$ Adjusted & & & \\
Arm circumference (AC) & 0.63 & $0.54-0.73$ & $<0.001$ \\
$\quad$ Unadjusted & 0.63 & $0.53-0.76$ & $<0.001$ \\
$\quad$ Adjusted & & & $<0.001$ \\
Waist circumference (WC) & & $0.91-0.97$ & $<0.001$ \\
$\quad$ Unadjusted & 0.94 & $0.90-0.97$ & \\
$\quad$ Adjusted & 0.93 &
\end{tabular}

OR: Odds Ratio; $95 \% C l: 95 \%$ Confidence interval; ${ }^{*} p<0.05$; Adjusted for age, sex, schooling, income, health perception, number of diseases and medications, hospitalization and occurrence of falls in the last year, smoking habit, level of physical activity, functional disability for basic and instrumental activities of daily life; Hosmer-Lemeshow test $(p>0.05)$

community-living older adults, with good predictive and discriminatory power [39]. However, the cut-off points that provided the best balance between sensitivity and specificity were $\leq 24.8 \mathrm{~kg} / \mathrm{m}^{2}$ and $\leq 24.5 \mathrm{~kg} / \mathrm{m}^{2}$ for BMI among men and women, respectively, and $\leq 27 \mathrm{~cm} \mathrm{AC}$ for both sexes.

Several studies have shown that anthropometric measurements are useful for the screening of sarcopenia associated with conditions of reduced muscle mass, falls, functionality, and mortality $[8,10,12,26,40,41]$. However, few studies have investigated and validated in a single population all the measurements proposed in the present study.

Regarding CC, the literature has reported a cut-off point of $<31 \mathrm{~cm}$ for the screening of sarcopenia [15, 19, $33,42-44]$. A study on the Korean population [8] (mean age: 76.2 years) also reported $\mathrm{CC}$ values differing from those reported here, i.e., $<35$ for men and $<33 \mathrm{~cm}$ for women. In the Japanese population [9] (mean age: 61 years for women and 63 years for men), it were obtained cut-off points for sarcopenia of $<34 \mathrm{~cm}$ for men and $<$ $33 \mathrm{~cm}$ for women, those exact values were also obtained in a Brazilian study [14] (60 years of age for women and 70 years of age for men). Since the above studies were conducted on an older population of different age ranges, it is difficult to compare their results with the present ones, which involved subjects with a mean age of 77 years. This is confirmed by other studies [10] which reported different and significant results between anthropometric measurements according to age ranges of $60-64,65-69,70-74,75-79$, and $>80$ years. 

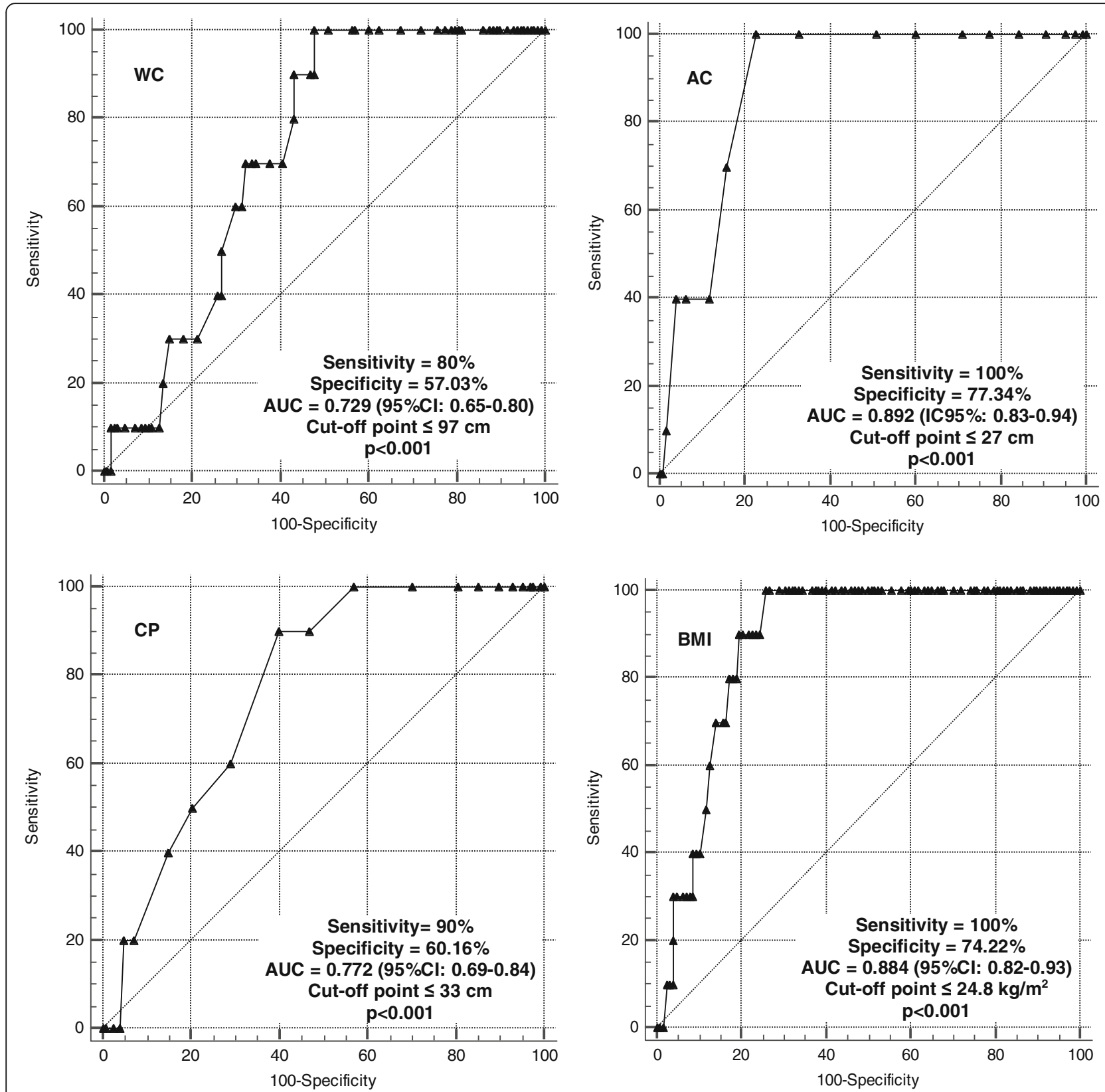

Fig. 1 Areas under the ROC curve for the anthropometric indicators as discriminants for the presence of sarcopenia among older men. AUC: area under the ROC curve; Cl: confidence interval; WC: waist circumference; AC: arm circumference; CC: calf circumference; BMI: body mass index

Another indicator that showed correlation with sarcopenia in the present study was WC, with cut-off points of $\leq 97 \mathrm{~cm}$ for men (sensitivity $=80 \%$ specificity $=57.03 \%$ ) and $\leq 86 \mathrm{~cm}$ for women (sensitivity: $60 \%$, specificity: $82,56 \%$ ). These results agree with previous study [7] with cut-off points of $92 \mathrm{~cm}$ for men (sensitivity: $79.5 \%$, specificity: $66.7 \%$ ) and $88 \mathrm{~cm}$ for women (sensitivity: 65.1\%, specificity $85.7 \%$ ). Also $\mathrm{WC}$, in addition to being a good indicator of sarcopenia, can also be used for the assessment of body composition and central obesity [7].
$\mathrm{AC}$ as a single indicator showed association with sarcopenia, with a significant difference from the nonsarcopenic group. The cut-off points obtained were $\leq 27$ $\mathrm{cm}$ for both sexes, with $100 \%$ sensitivity and $77.34 \%$ specificity for men and de $100 \%$ sensitivity and $70.54 \%$ for women. Other studies $[10,25]$ used corrected arm muscle area and obtained results different from the present ones, with cut-off points of $24.7 \mathrm{~cm}, 23.8 \mathrm{~cm}$ and $21 \mathrm{~cm}$ for men and $23.3 \mathrm{~cm}, 24.7 \mathrm{~cm}, 23.9 \mathrm{~cm}$ e $19.8 \mathrm{~cm}$ for women. However, this difference may be justified by the fact that the researchers assessed older subjects aged on average 71.2 

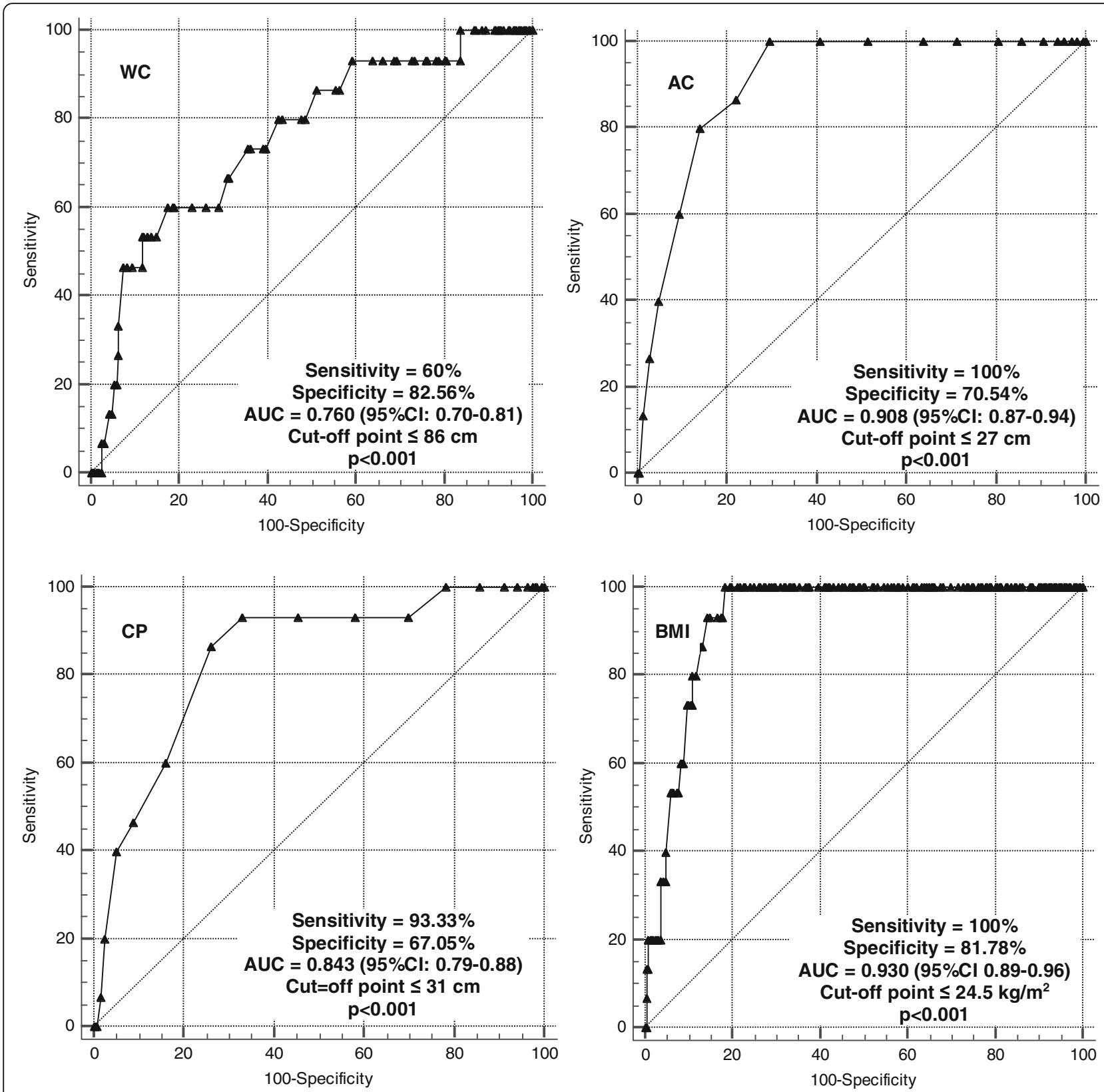

Fig. 2 Areas under the ROC curve for the anthropometric indicators as discriminants for the presence of sarcopenia among older women. AUC: area under the ROC curve; Cl: confidence interval; WC: waist circumference; AC: arm circumference; CC: calf circumference; BMI: body mass index

years [10] and subjects older than 80 years [25], i.e., older populations than the sarcopenic population investigated here. Although, AC is a valid measure [45] since these authors observed that corrected muscle area is strongly correlated with DEXA for lean mass data. In addition, the AC is the region least susceptible to changes in circumference caused by fluid retention, such as the edema that occurs in the lower limbs [10].

According to data from the present study, the BMI proved to be an acceptable anthropometric instrument for screening sarcopenia for both sexes, with good sensitivity and specificity. This agrees with another study [7] who reported similar cut-off points for BMI with our data [ $\leq 24.6$ for men (sensitivity: $84.9 \%$, specificity: $63.3 \%$ ) and $\leq 26.2$ for women (sensitivity: $74.6 \%$, specificity: $85.7 \%)$ ]. Besides, the BMI and advanced age are strongly associated with low musculoskeletal index (appendicular skeletal muscle mass/height) [12].

Anthropometric indicators are easily applied, representing useful measures recommended as part of a screening process since they can be easily obtained at primary health care centers $[5,15,32,46-48]$. Thus, taking together the 
information from the present study with the updated recommendation from EWGSOP2 [19], it is proposed for screening sarcopenia an easy pathway to identify people with sarcopenia or its risk, and following this perspective, our data have shown that anthropometric measures could also be an additional and relevant strategy to detected sarcopenia indicators in remote areas such as the Amazon region of the country, mainly in view of the tendency to population aging in Brazil [49].

This data also indicates [49] the existence of a significant population contingent that does not reach the level of consumption of $1900 \mathrm{kcal}$ per day and that is characterized by the consumption of foods with high fat, sugar and salt concentrations, poor variety, and a low consumption of fruits and vegetables. Likewise, reduction in protein intake has been related to the reduction of muscle mass, with a lean mass reduction of as much as $40 \%$ within 3 years without the ideal protein intake, which should be about $1-1.2 \mathrm{~g} / \mathrm{kg}$ [50].

Moreover, it have been reported that several factors may interfere with the prevalence of older adults with sarcopenia such as age, sex, nutrition, geographical region, in addition to individual factors such as percentage of muscle mass, muscle strength and functional capacity [51]. Such factors may explain the divergence of the results obtained here both in relation to studies conducted in developed countries and studies conducted in other regions of Brazil. In Brazil, by the way, the prevalence of sarcopenia was $15.4 \%$ in São Paulo-SP [51], 10.8 to $18 \%$ among older subjects from Rio de Janeiro-RJ [52], 15.9\% in from Pelotas-RS [13] and $17.8 \%$ in Lafaiete CoutinhoBA [15]. This clearly shows that divergence exists regarding the characteristics of the population among regions even within the same country.

Some limitations of the study should be considered. The use of the total muscle mass equation [22] offers an estimated calculation; however, it is a method of easy application that does not require expensive equipment and that has been validated and extensively used. Also, by being a cross-sectional study, the present investigation did not permit to infer causality relations between the variables studied. On the other hand, the study provides information about a representative sample of community-living older adults from a municipality of the Amazon region.

In Brazil, the older population increases considerably each year. The vast territory of the country poses many challenges, one of them being, among other aspects, the understanding of how the population aging is occurring in each region. It should be pointed out that a parcel of the population residing in the northern region lives in areas of difficult access for both older people and health agents, aspects that can impair the implementation of actions. Thus, it is clearly important to identify new tools of easy access and handling for the early screening of sarcopenia, especially among older adults living in the northern region of Brazil. According to the results of the present study, anthropometric measures proved to be effective for this purpose, thus permitting the development of new preventive and therapeutic strategies for this population.

\section{Conclusion}

Sarcopenic older adults had lower mean values of anthropometric measurements than non-sarcopenic subjects. An increase of one unit of these indicators may reduce the probability of the occurrence of sarcopenia among community-living older adults. All anthropometric indicators were considered to discriminate for sarcopenia with the cut-off points for BMI and AC showing a better equilibrium in the sensitivity and specificity relationship.

\section{Supplementary Information}

The online version contains supplementary material available at https://doi. org/10.1186/s12877-020-01923-y.

Additional file 1.

\section{Abbreviations}

AC: Arm circumference; WC: Waist circumference; CC: Calf circumference; BMI: Body mass index; OR: Odds ratio; Cl: confidence intervals; DXA: Dualenergy X-ray emission absorptiometry; MR: Magnetic resonance; CT: Computed tomography; WHO: World Health Organization;

AbC: Abdominal circumference; MMSE: Mini Mental State Examination; EWGSOP 2: European Working Group on Sarcopenia in Older People; TMM: Total muscle mass; MMI: Muscle mass index; HGS: Handgrip strength; BADL: Basic activities of daily life; IADL: Instrumental activities of daily life; IPAQ: International Physical Activity Questionnaire; ROC: Receiver Operating Characteristic; SPSS: Statistical Package for the Social Sciences; AUC: Area under the ROC curve

\section{Acknowledgements}

Not applicable.

\section{Authors' contributions}

DGO, MSP, APM, VTKF and NCRI contributed to the conception of the project and to a critical revision and approved the version to be published; CLE contributed to the conception, design and writing of the paper; MSP contributed to data analysis and to text writing. All authors reviewed and approved the manuscript.

\section{Funding}

This research was financed by the Foundation for Research Support of the State of Amapá (FAPEAP, Concession n² 250.203.029/2016). This research agency had no influence on the design of the study, in the collection, analysis and interpretation of data, and in writing the manuscript.

\section{Availability of data and materials}

The datasets used and/or analysed during the current study are available from the corresponding author on reasonable request.

Ethics approval and consent to participate

This study received approval from the Research Ethics Committee of the Federal University of Amapá, number 1.738.671. All participants provided their written informed consent. 


\section{Consent for publication}

Not applicable.

\section{Competing interests}

The authors declare that they have no competing interests.

Received: 10 March 2020 Accepted: 22 November 2020

Published online: 01 December 2020

\section{References}

1. Cruz-Jentoft AJ, Sayer AA. Sarcopenia. Lancet. 2019;393(10191):2636-46. https://doi.org/10.1016/S0140-6736(19)31138-9..

2. Cruz-Jentoft AJ, Landi F, Schneider SM, et al. Prevalence of and interventions for sarcopenia in ageing adults: A systematic review. Report of the International Sarcopenia Initiative [EWGSOP and IWGS]. Age Ageing. 2014;43(6):48-759. https://doi.org/10.1093/ageing/afu115.

3. Diz JBM, Leopoldino AAO, de Souza Moreira B, Henschke N, Dias RC, Pereira LSM, et al. Prevalence of sarcopenia in older Brazilians: A systematic review and meta-analysis. Geriatr Gerontol Int. 2017;17(1):5-16. https://doi.org/10. $1111 /$ ggi.12720.

4. Visvanathan R, Chapman I. Preventing sarcopaenia in older people Maturitas. 2010;66(4):383-8. https://doi.org/10.1016/j.maturitas.2010.03. 020.

5. Yu S, Appleton S, Chapman I, et al. An anthropometric prediction equation for appendicular skeletal muscle mass in combination with a measure of muscle function to screen for sarcopenia in primary and aged care. J Am Med Dir Assoc. 2015;16(1):25-30. https://doi.org/10.1016/j.jamda.2014.06.018.

6. Lustgarten MS, Fielding RA. Assessment of analytical methods used to measure changes in body composition in the elderly and recommendations for their use in phase II clinical trials. J Nutr Heal Aging. 2011;15(5):368-75. https://doi.org/10.1007/s12603-011-0049-x.

7. Confortin SC, Meneghini V, Ono LM, Schneider IJC, Barbosa AR, D'Orsi E. Anthropometric indicators as a screening tool for sarcopenia in older adults from Florianópolis, Santa Catarina: EpiFloripa ageing study. Rev Nutr. 2017; 30(3):287-96. https://doi.org/10.1590/1678-98652017000300002.

8. Kim S, Kim M, Lee Y, Kim BS, Yoon TY, Won CW. Calf circumference as a simple screening marker for diagnosing sarcopenia in older Korean adults: the Korean frailty and aging cohort study [KFACS]. J Korean Med Sci. 2018; 33(20):1-10. https://doi.org/10.3346/jkms.2018.33.e151.

9. Kawakami R, Murakami H, Sanada K, et al. Calf circumference as a surrogate marker of muscle mass for diagnosing sarcopenia in Japanese men and women. Geriatr Gerontol Int. 2015;15(8):969-76. https://doi.org/10.1111/ggi. 12377.

10. Akin S, Mucuk S, Öztürk A, et al. Muscle function-dependent sarcopenia and cut-off values of possible predictors in community-dwelling Turkish elderly: calf circumference, midarm muscle circumference and walking speed. Eur J Clin Nutr. 2015:69(10):1087-90. https://doi.org/10.1038/ejcn.2015.42.

11. World health organization. WHO 1995 Physical status. Use and anthropometry. 1995. [WHO technical report series no. 8].

12. Beaudart C, McCloskey E, Bruyère $\mathrm{O}$, et al. Sarcopenia in daily practice: assessment and management. BMC Geriatr. 2016;16(1):1-10. https://doi.org/ 10.1186/s12877-016-0349-4

13. Barbosa-Silva TG, Bielemann RM, Gonzalez MC, Menezes AMB. Prevalence of sarcopenia among community-dwelling elderly of a medium-sized south American city: results of the COMO VAl? Study. J Cachexia Sarcopenia Muscle. 2016;7(2):136-43. https://doi.org/10.1002/jcsm.12049.

14. Pagotto VI. Ferreira dos Santos KI, Gomes Malaquias SI, et al. calf circumference: clinical validation for evaluation of muscle mass in the elderly. Rev Bras Enferm. 2018;71(2):343-50. https://doi.org/10.1590/00347167-2017-0121.

15. Pinheiro PA, da Silva Coqueiro R, Carneiro JAO, Correia TML, Pereira R, Fernandes $\mathrm{MH}$. Anthropometric indicators as screening tools for sarcopenia in older adult women. Enferm Clin. 2019;S1130-8621(19):30041-5. https:// doi.org/10.1016/j.enfcli.2018.12.010.

16. Instituto Brasileiro de Geografia e Estatística, 2010. Cidades. Macapá. Available: https://cidades.ibge.gov.br/brasil/ap/macapa/pesquisa/23/25359. Accessed 02 december 2019.

17. Santos Filho H, Almeida MG, Ribeiro MM. Mapeamento e classificação das áreas de ressaca na região metropolitana de Macapá-AP utilizando imagens do satélite CBERS-2B. Anais XVI Simp Bras Sensoriamento Remoto - SBSR,
2013; 2211-17. Available: https://www2.unifap.br/herondino/files/2018/06/ p0108.pdf. Accessed 02 december 2019.

18. Neri SHA. A utilização das ferramentas de geoprocessamento para identificação de comunidades expostas a hepatite a nas áreas de ressacas dos municípios de Macapá e Santana. Rio de Janeiro: Federal University of Rio de Janeiro; 2004

19. Cruz-Jentoft AJ, Bahat $G$, Bauer J, Boirie $Y$, Bruyère $O$, Cederholm $T$, et al. Sarcopenia: revised European consensus on definition and diagnosis. Age Ageing. 2019;48(1):16-31. https://doi.org/10.1093/ageing/afy169.

20. Ohara DG, Pegorari MS, Oliveira dos Santos NL, et al. Respiratory muscle strength as a discriminator of sarcopenia in community-dwelling elderly: a cross-sectional study. J Nutr Heal Aging. 2018;22(8):952-8. https://doi.org/10. 1007/s12603-018-1079-4.

21. Bertolucci PHF, Brucki SMD, Campacci SR, JuliaPno Y. O mini exame do estado mental em uma população geral: impacto da escolaridade. Arquivos de Neuropsiquiatria. 1994. https://doi.org/10.1590/S0004 $282 \times 1994000100001$

22. Lee RC, Wang Z, Heo M, Ross R, Janssen I, Heymsfield SB. Total-body skeletal muscle mass: development and cross-validation of anthropometric prediction models. Am J Clin Nutr. 2018;72(3):796-803. https://doi.org/10. 1093/ajcn/72.3.796.

23. Rech CR, Dellagrana RA, Marucci MFN, et al. Validity of anthropometric equations for the estimation of muscle mass in the elderly. Rev Bras Cineantropom Desempenho Hum. 2012;14:23-31. https://doi.org/10.5007/ 1980-0037.2012v14n1p23.

24. Ohara DG, Pegorari MS, Oliveira dos Santos NL, et al. Cross-Sectional Study on the Association Between Pulmonary Function and Sarcopenia in Brazilian Community-Dwelling Elderly from the Amazon Region. J Nutr Heal Aging. 2019. https://doi.org/10.1007/s12603-019-1290-y.

25. Delmonico MJ, Harris TB, Lee JS, et al. Alternative definitions of sarcopenia, lower extremity performance, and functional impairment with aging in older men and women. J Am Geriatr Soc. 2007;55(5):769-74. https://doi.org/ 10.1111/j.1532-5415.2007.01140.x.

26. Landi $F$, Calvani $R$, Tosato $M$, et al. Impact of physical function impairment and multimorbidity on mortality among community-living older persons with sarcopaenia: results from the ilSIRENTE prospective cohort study. BM Open. 2016;6(7):1-7. https://doi.org/10.1136/bmjopen-2015-008281.

27. American Society of Hand Therapists [ASHT]. Clinical Assessment Recommendations. Chigaco; 1992. Accessed 19 June 2018. https://www. asht.org/practice/clinical-assessment-recommendations.

28. Dodds RM, Syddall HE, Cooper R, Benzeval M, Deary IJ, Dennison EM, Der G, et al. Grip strength across the life course: normative data from twelve British studies. PLoS One. 2014;9(12):e113637. https://doi.org/10.1371/journal.pone. 0113637.

29. Frisancho AR. New standards of weight and body composition by frame size and height for assessment of nutritional status of adults and the elderly. Am J Clin Nutr. 1984;40(4):808-19. https://doi.org/10.1093/ajcn/40.4. 808.

30. Zhang $L$, Shen $Y$, Zhou J, et al. Relationship between waist circumference and elevation of carotid intima-media thickness in newly-diagnosed diabetic patients. Biomed Environ Sci. 2014;27(5):335-42. https://doi.org/10. 3967/bes2014.058

31. Callaway CW, Chumlea WC, Bouchard C, et al. Anthropometric standardization reference manual. 1st ed. USA: Human Kinetics Books; 1988. p. $39 \mathrm{e} 55$.

32. Tosato M, Marzetti $\mathrm{E}$, Cesari M, et al. Measurement of muscle mass in sarcopenia: from imaging to biochemical markers. Aging Clin Exp Res. 2017; 29(1):19-27. https://doi.org/10.1007/s40520-016-0717-0.

33. Benedetti TRB, Mazo GZ, Barros MVG. Aplicação do Questionário Internacional de Atividades Físicas para avaliação do nível de atividades físicas de 15 mulheres idosas: validade concorrente e reprodutibilidade teste-reteste. R. bras. Ci. e Mov. Brasília. 2004. doi: https://doi.org/10.18511/ rbcm.v12i1.538.

34. WHO expert Consultation. Waist Circumference and Waist-Hip Ratio Report of a WHO Expert Consultation. World Health. 2008;[December]:8-11. doi: https://doi.org/10.1038/ejcn.2009.139.

35. Madden AM, Smith S (2016) Body composition and morphological assessment of nutritional status in adults: A review of anthropometric variables. J Hum Nutr Diet 29:7-25. https://doi.org/10.1111/jhn.12278.

36. Lino VTS, Pereira SRM, Camacho LAB, Ribeiro Filho ST, Buksman S Adaptação transcultural da Escala de Independência em Atividades da Vida 
Diária [Escala de Katz]. Cad Saude Publica. 2008;24(1):103-12. https://doi.org/ 10.1590/s0102-311×2008000100010.

37. Santos RL, Júnior JSV. Confiabilidade da versão brasileira da Escala de Atividades Instrumentais da Vida Diária. Rev Bras em Prom da Saud. 2008; 21(1):290-6.

38. Guralnik JM, Simonsick EM, Ferrucci L, Glynn RJ, Marcel E, Salive MPH, Wallace RB. Lower-extremity function in persons over the age of 70 years as predictor of subsequent disability. N Engl J Med. 1995;332(9):556-61. https:// doi.org/10.1056/NEJM199503023320902.

39. Nakano MM. Versão Brasileira da Short Physical Performance Battery - SPPB: Adaptação Cultural e Estudo da Confiabilidade [Dissertation]. Faculdade de Educação: Universidade Estadual de Campinas; 2007.

40. Saka B, Ozkaya H, Karisik E, et al. Malnutrition and sarcopenia are associated with increased mortality rate in nursing home residents: a prospective study. Eur Geriatr Med. 2016;7(3):232-8. https://doi.org/10.1016/j.eurger.2015. 12.010.

41. Tsai AC, Chang T-L. The effectiveness of BMI, calf circumference and midarm circumference in predicting subsequent mortality risk in elderly Taiwanese. Br J Nutr. 2011;105(2):275-81. https://doi.org/10.1017/ s0007114510003429.

42. Bastiaanse LP, Hilgenkamp TIM, Echteld MA, Evenhuis HM. Prevalence and associated factors of sarcopenia in older adults with intellectual disabilities. Res Dev Disabil. 2012;33(6):2004-12. https://doi.org/10.1016/j.ridd.2012.06.002.

43. Rolland $Y$, Lauwers-Cances V, Cournot M, et al. Sarcopenia, calf circumference, and physical function of elderly women: a cross-sectional study. J Am Geriatr Soc. 2003;51(8):1120-4. https://doi.org/10.1046/j.15325415.2003.51362.x.

44. Velazquez-Alva MC, Irigoyen Camacho ME, Lazarevich I, Delgadillo Velazquez J, Acosta Dominguez P, Zepeda Zepeda MA. Comparison of the prevalence of sarcopenia using skeletal muscle mass index and calf circumference applying the European consensus definition in elderly Mexican women. Geriatr Gerontol Int. 2017;17(1):161-70. https://doi.org/10. 1111/ggi.12652.

45. Noori N, Kopple JD, Kovesdy CP, et al. Mid-arm muscle circumference and quality of life and survival in maintenance hemodialysis patients. Clin J Am Soc Nephrol. 2010;5(12):2258-68. https://doi.org/10.2215/CJN.02080310.

46. Bruyère $\mathrm{O}$, Beaudart $\mathrm{C}$, Reginster $\mathrm{J}$, et al. Assessment of muscle mass, muscle strength and physical performance in clinical practice: an international survey. Eur Geriatr Med. 2016;7(3):243-6. https://doi.org/10. 1016/j.eurger.2015.12.009

47. Heymsfield SB, Gonzalez MC, Lu J, Jia G, Zheng J. Skeletal muscle mass and quality: evolution of modern measurement concepts in the context of sarcopenia. Proc Nutr Soc. 2015;74(4):355-66. https://doi.org/10.1017/ s0029665115000129.

48. Perissinotto E, Pisent C, Sergi G, Grigoletto F, Enzi G. Anthropometric measurements in the elderly: age and gender differences. Br J Nutr. 2002; 87(2):177-86. https://doi.org/10.1079/bjn2001487.

49. Brasil, Ministério da Saúde. [2005]. Estudo de Caso Brasil: A Integração Das Açães de Alimentação e Nutrição Nos Planos de Desenvolvimento Nacional Para Alcance Das Metas Do Milênio No Contexto Do Direito Humano à Alimentação Adequada 2005, ISBN 85-334-0878-1. http://bvsms.saude.gov. br/bvs/publicacoes/estudo_caso_brasil_alimentacao_adequada.pdf.

50. Shaw SC, Dennison EM, Cooper C. Epidemiology of sarcopenia: determinants throughout the Lifecourse. Calcif Tissue Int. 2017;101(3):22947. https://doi.org/10.1007/s00223-017-0277-0.

51. Alexandre TDS, Duarte YADO, Santos JLF, Wong R, Lebrão ML. Prevalence and associated factors of sarcopenia among elderly in Brazil: findings from the sabe study. J Nutr Heal Aging. 2014;18(3):284-90. https://doi.org/10. 1007/s12603-013-0413-0.

52. Moreira VG, Perez M, Lourenço RA. Prevalence of sarcopenia and its associated factors: the impact of muscle mass, gait speed, and handgrip strength reference values on reported frequencies. Clinics. 2019. https://doi. org/10.6061/clinics/2019/e477.

\section{Publisher's Note}

Springer Nature remains neutral with regard to jurisdictional claims in published maps and institutional affiliations.

\section{Ready to submit your research? Choose BMC and benefit from:}

- fast, convenient online submission

- thorough peer review by experienced researchers in your field

- rapid publication on acceptance

- support for research data, including large and complex data types

- gold Open Access which fosters wider collaboration and increased citations

- maximum visibility for your research: over $100 \mathrm{M}$ website views per year

At BMC, research is always in progress.

Learn more biomedcentral.com/submissions 